\title{
Elemental diets in the treatment of Crohn's disease
}

\author{
C. O'Morain, Division of Clinical Sciences, Clinical Research Centre, Watford \\ Road, Harrow, Middlesex $H A$ I $3 U \mathcal{F}$
}

Crohn's disease is an inflammatory bowel disease the aetiology of which is unknown. It was first described 47 years ago (Crohn et al. 1932). There appears to be a real increase in its incidence in the last 20 years. A working definition of Crohn's disease is 'a condition in which there is a chronic enteritis usually characterized by areas of intestinal stenosis, and pathologically by non-caseating granulomata in the bowel wall' (Weterman et al. 1975). As the definition implies the diagnosis is made on clinical, radiological and histological grounds. The clinical picture of patients with Crohn's disease is that of weight loss, abdominal pain, diarrhoea and stunted growth in children. They may have extra-intestinal manifestations such as pyrexia, uveitis and arthritis.

\section{Treatment}

The treatment of Crohn's disease can be divided into five main categories: surgery, general symptomatic and supportive treatment, antimicrobial treatment, anti-inflammatory treatment and nutritional treatment. Resection of the affected bowel was once thought to be the definitive treatment but recurrence of the disease is common and now surgery is reserved for the complications of Crohn's disease unresponsive to medical therapy such as obstruction, unremitting inflammation and haemorrhage, toxic megacolon, free perforation and fistula formation. The aim of medical treatment is to induce a remission. No treatment has been shown to produce a permanent cure for Crohn's disease. As the disease course is characterized by its chronicity and morbidity a lot of emphasis is placed on symptomatic and supportive treatment. This would include anxiolytic, analgesic and anti-diarrhoeal agents. Broad spectra antibiotics are used for the complications of Crohn's disease such as abscess formation or perforation. There have been reports that Metronidazole (Ursing \& Kamme, 1975) and broad spectra antibiotics (Moss et al. 1978) are effective treatment in acute Crohn's disease. There are three types of drugs in the anti-inflammatory group: corticosteroids, azothiaprine and salazopyrine. Corticosteroids have been shown to be more effective than azothiaprine or salazopyrine (Singleton, 1976). Nutritional therapy is a new concept introduced in the treatment of Crohn's disease when it was found that patients were in negative nitrogen balance. There are two methods of putting patients into positive $\mathrm{N}$ balance, either by parenteral nutrition or the use of an elemental diet. 


\section{Elemental diets}

An elemental diet means that the food is given in the simplest formulation: protein as amino acids, carbohydrate as glucose, fat as fatty acids. Fatty acids are insoluble with amino acids and are given as safflower oil or medium chain triglycerides. Reports of the use of elemental diets in the treatment of Crohn's disease are few and most are from surgical units in which patients admitted with surgical indications for intervention are placed on an elemental diet. Not only do they improve metabolically but their indications for surgery resolve (Stephenson et al. 1972; Giorgini et al. 1973; Voitk et al. 1973; Rocchio et al. 1974; Goode et al. 1976; Segal et al. 1977).

We have been using an elemental diet in the treatment of Crohn's disease for some time now. The elemental diet we use is Vivonex. We aim at giving the

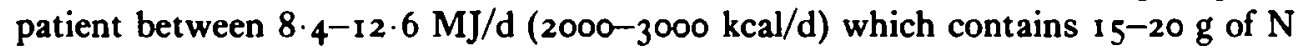
in the form of pure amino acids. The diet is introduced over a period of $3 \mathrm{~d}$, increasing the strength on successive days. The diet is taken orally and all other foods are prohibited except for tea and coffee without milk, and they are allowed boiled sweets to suck. We maintain the patient on the diet for 4 weeks and monitor the progress both clinically and biochemically at weekly intervals. We reintroduce food slowly over a period of $3 \mathrm{~d}$ by increasing the consistency from fluid to solid.

\section{Results}

We have treated twenty-four patients with Crohn's disease with an elemental diet. All the patients were so disabled that they required hospitalization. Their age ranged from 7 to 71 years (eighteen male and six female). Eleven of the patients had small bowel disease, four had large bowel disease and nine had both large and small bowel disease. Twenty-two of twenty-four patients completed the 4-week course. Only one patient discontinued on account of the diet's unpalatability. The second patient who did not complete the course made such a dramatic improvement in two weeks that it was thought unnecessary to persist with the diet. Twenty-one of the patients were judged to be in clinical and biochemical remission at the end of the course of treatment. One of the patients, a 21 -year-old male with small bowel Crohn's disease who had obstructive symptoms, failed to respond and was referred for surgical intervention. Fig. I shows the changes in various indices during the 4 -week course. Although there was an improvement in each of the parameters, only the fall in the erythrocyte sedimentation rate reached significant levels. The mean hospitalization stay for the patients was $13 \mathrm{~d}$ and all of the patients were able to resume their everyday activity. A more accurate evaluation of the efficacy of an elemental diet is obtained if a patient is followed for a longer period of time. Fig. 2 depicts the height and weight of a patient who presented at the age of 17 with a height lower than the third percentile. He was also pre-pubertal. On investigation he was found to have small bowel Crohn's disease. He was tried on various medication to no avail. He was eventually put on an elemental diet. He made a dramatic response in both height and weight and he went through puberty. 
Vol. $3^{8}$
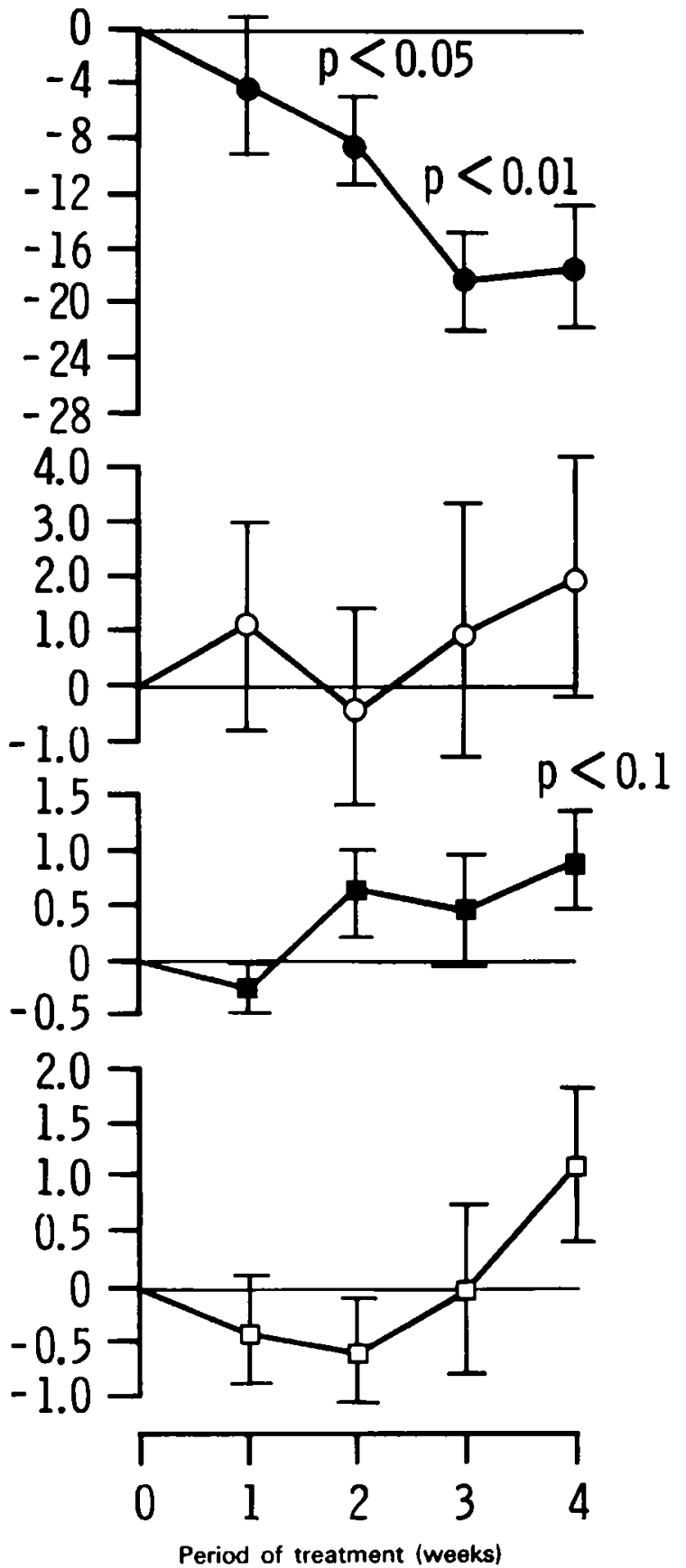

Fig. 1. Effect of an elemental diet on various indices of disease activity in Crohn's disease. (O), ESR change $(\mathrm{mm} / \mathrm{h}) ;(O)$, albumin change $(\mathrm{g} / \mathrm{l}) ;(\square)$, haemoglobin change $(\mathrm{g} / \mathrm{dl}) ;(\square)$, weight change (kg). Mean values with SEMs represented by vertical bars. 


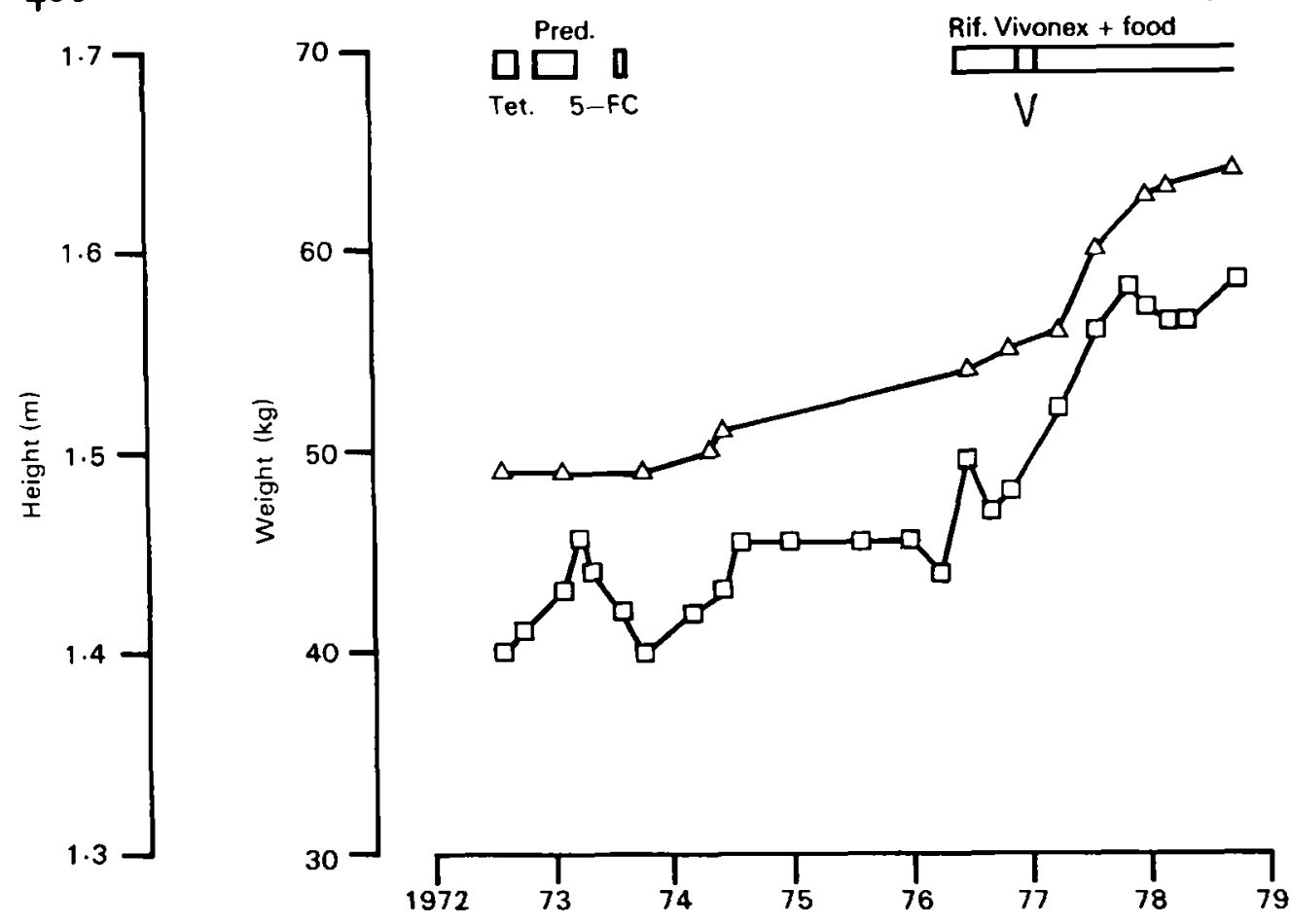

Fig. 2. Effect of an elemental diet on height $(\Delta ; \mathrm{m})$ and weight $(\square ; \mathrm{kg})$ in a $\mathrm{i} 7$-year-old male with small bowel Crohn's disease. Tet, tetracycline; Rif, Rifampicin; Pred, Prednisone; V, Vivonex; $5^{-\mathrm{FC}}, 5$ fluorocysteine.

\section{Discussion}

These results suggest that an elemental diet may be primary treatment in acute Crohn's disease. The possible modes of action of the diet are; putting the patient into positive $\mathbf{N}$ balance, acts as a medical bypass, it is non-allergenic, changes the bowel flora, contains hypertonic glucose and effects neutrophil function. We have studied $\mathrm{N}$ balance using radiolabelled yeast protein and monitoring protein distribution, retention and excretion in two patients with acute Crohn's disease, before and after treatment. One of these patients went into positive $\mathrm{N}$ balance; the second patient, although he improved clinically and biochemically, was found to be still in negative $\mathrm{N}$ balance at the end of treatment. This raised the possibility that an elemental diet acts in some other way than merely placing the patient in positive $\mathrm{N}$ balance. An elemental diet acts as a medical bypass in that it is rapidly absorbed in the upper gastrointestinal tract. It does not contain any indigestible bulk and there is evidence that it decreases production of digestive juices, both pancreatic and gastric (McArdle et al. 1972).

By decreasing the intestinal secretion it gives a chance for the bowel to rest and for the inflammation to resolve. The original study done with an elemental diet in the United States (Winitz et al. 1970) working on the American space programme has shown that an elemental diet has the effect of decreasing the number of bacteria isolated from the stools. Other workers (Attebury et al. 1972; Crowther et al. 1973; Bounous et al. 1974) have failed to show this dramatic effect using more 
sensitive techniques but they did find specific changes in various bacterial colonies on volunteers placed on an elemental dict. We have looked at this in seven patients with Crohn's disease treated with an elemental diet. We have failed to show any change before and after a period of treatment in the total number of bacteria or in specific colony types. An elemental diet is non-allergenic in that it contains no whole protein. Excluding foreign proteins may resolve some of the systemic manifestations of Crohn's disease and also allow the ulcerated bowel to heal. The main energy source in an elemental diet is glucose. Hypertonic glucose has been shown to cause small bowel relaxation in vitro, but it is conjectural if this can cause regression of intestinal stenosis in vivo. Patients with Crohn's disease appear to have neutrophil dysfunction in that the number of neutrophils migrating into a skin-window chamber are abnormally low (Segal et al. 1976). In this test, a relatively simple one, the forearm of the patient is abraded to induce a superficial inflammation and then covered by a plastic skin-window chamber into which the patient's own serum is inserted. The skin-window chamber is left on for $5 \mathrm{~h}$; after this period the number of cells that have migrated into the chamber are counted and we have found that in patients with Crohn's disease the number of cells migrating is significantly lower than in patients with other gastrointestinal conditions such as ulcerative colitis, peptic ulcer, gall-bladder disease, coeliac disease and in healthy controls. We have looked at this parameter before and after treatment in six patients. In four of the patients there was no change in the number of cells migrating in the skin-window chambers. In two patients there was a significant increase in the number of cells migrating and their cell migration after a period of treatment approached normal.

\section{Conclusion}

The most likely explanation of the effect of an elemental diet is probably a combination of all the proposed factors. We are investigating each of these possibilities. Our results are so encouraging that we are now comparing the efficacy of an elemental diet with that of steriods in a more controlled fashion by randomizing patients either to the elemental diet treatment regime or to steroids.

\section{REFERENCES}

Attebury, H. R., Sutter, V. I. \& Finegold, S. M. (1972). Am. J. clin, Nutr. 25, 1391.

Bounous, G. \& Dervoede, G. J. (1974). Gastroenterology 66, 210.

Crohn, B. B., Ginzburg, L. \& Oppenheimer, G. D. (1932). F. Am. Med. Assoc. 99, 1323.

Crowther, J. S., Drasar, B. S., Goddard, P., Hill, M. J. \& Johnson, K. (1973). Gut 14, 790.

Giorgini, G. I., Stephens, R. V. \& Thayer, W. R. (1973). Am. J. dig. Dis. 18, 153.

Goode, A., Hawkins, T., Feggetter, J. G. W. \& Johnston, I. D. A. (1976). Lancet i, 122.

McArdle, A. H., Brown, R. A., Echave, V., Rivilis, J. \& Thompson, A. G. (1972). Archs Mal. Appar. dig. 61, $115 \mathrm{c}$.

Moss, A. A., Carbone, J. V. \& Kressel, H. Y. (1978). Am. f. Roentg. 131, 787.

Rocchio, M. A., Chung-Ja Mo Chu, Haar, K. F. \& Randall, H. T. (1974). Am. J. Surg. 127, 469.

Segal, A. \& Loewi, G. (1976). Lancet ii, 219.

Segal, A. W., Levi, A. J. \& Loewi, G. (1977). Lancet ii, 382.

Singleton, J. W. (1976). Gastroenterology 76, 938. 
Stephenson, R. V., Burg, K. D., De Luca, F. D. \& Randall, H. T. (1972). Am. J. Surg. 123, 374. Ursing, B. \& Kamme, C. (1975). Lancet i, 775.

Voitk, A. J., Echave, V., Feller, J. H., Brown, R. A. \& Gurd, F. N. (1973). Archs Surg., Chicago $107,329$.

Weterman, I. T., Pena, A. S. \& Booth, C. C. (1975). Excerpta med.

Winitz, M., Adams, R. F., Seedman, D. A., Davis, P. N., Jayko, L. G. \& Hamilton, J. A. (1970). Am. J. clin. Nutr. 23, 546 . 